\title{
BAHASA ARAB, BUDAYA LOKAL, DAN LITERASI TAFSIR DALAM PENGEMBANGAN BUDAYA ISLAM DI SULAWESI SELATAN
}

\author{
Muhammad Yusuf \\ Sekolah Tinggi Agama Islam Al-Furqan Makassar, Indonesia E-mail: \\ muh.yusuf1274@gmail.com \\ Ismail Suardi Wekke \\ Sekolah Tinggi Agama Islam Negeri Sorong Papua Barat \\ E-mail: Iswekke@gmail.com \\ Baharuddin HS \\ Universitas Islam Negeri Alauddin Makassar \\ E-mail: $\underline{\text { hbaharuddin@gmail.com }}$
}

\begin{abstract}
Abstrak: Tulisan ini merupakan kajian terhadap peran bahasa Arab, budaya Bugis, dan literasi tafsir dalam pengembangan kebudayaan Islam pada masyarakat Bugis. Dengan melakukan identifikasi beberapa kosakata bahasa Arab yang diserap kedalam bahasa Bugis, akan tampak pengaruhnya. Selain merupakan bahasa yang sangat kaya dengan kosakatanya dan ketinggian sastranya, bahasa Arab juga didukung oleh posisi alQur'an dan Hadis sebagai sumber primer ajaran Islam. Tersebarnya Islam ke berbagai daerah, khususnya di Sulsel, meniscayakan masyarakat lokal mengenal bahasa Arab. Bahasa Bugis telah banyak mengadaptasi istilah Arab dan Islam. Dengan masuknya Islam di Sulawesi Indonesia berpengaruh besar terhadap kebudayaan Bugis-Makassar. Dimasukkan sara' dalam sistem Pangadereng sebagai sistem kehidupan masyarakat Bugis telah banyak memberi pengaruh terhadap perkembangan kebudayaan Islam bagi masyarakat Bugis. Inilah yang dikenal istilah al- 'urf sebagai salah satu pertimbangan pembentukan hukum Islam. Selain itu, penulisan lietratur terjemah dan tafsir berbahasa Bugis menjadikan Lontarak sebagai medium penjelasan al-Qur'an. Meskipun Islam tidak identik dengan Bugis sebagaimana Islam tidak identik dengan Arab, namun Islam dan Bugis memiliki banyak kesamaan, sehingga Islam mudah diterima oleh orangorang Bugis.
\end{abstract}

Kata Kunci: Bahasa Arab, Budaya lokal, tafsir, kebudayaan Islam

\section{INTRODUCTION}

Aktualisasi Islam dalam lintasan sejarah telah menjadikan Islam tidak dapat dilepaskan dari aspek lokalitas. Masing-masing dengan karakteristiknya sendiri mencerminkan nilai-nilai ketauhidan sebagai unity yang mengikat secara kokoh satu sama lain. Islam dalam sejarah yang beragam merupakan penerjemahan Islam 
universal ke dalam realitas kehidupan umat manusia. ${ }^{1}$ Relasi antara Islam sebagai agama dengan budaya lokal sangat jelas dalam kajian antropologi agama. Dalam perspektif ini diyakini bahwa agama merupakan penjelmaan dari sistem budaya. ${ }^{2}$ Berdasarkan teori ini, Islam sebagai agama samawi dianggap sebagai penjelmaan dari sistem budaya suatu masyarakat muslim. Islam sebagai agama, kebudayaan, dan peradaban besar dunia yang masuk ke Indonesia pada abad ke-7 dan terus berkembang hingga kini, telah memberi banyak kontribusi terhadap keanekaragaman kebudayaan Nusantara.

Relasi bahasa Arab, Islam, dan lokalitas memiliki hubungan yang sangat erat. Istilah-istilah Arab dan Islam yang diadaptasi kedalam bahasa Bugis hampir tidak hitung jumlahnya. Bahasa Arab dan istilah-istilah Islam telah turut berpengaruh secara signifikan terhadap pengembangan budaya lokal Bugis. Apalagi ketika Islam diterima sebagai bagian dari sistem kehidupan masyarakat Bugis dengan istilah Sara' (syara'/agama).

Setelah Islam menjadi agama resmi di Sul-Sel yang dibawa oleh orang Melayu, maka tradisi tulis mulai berkembang dengan penulisan naskah-naskah di daerah ini, baik dalam bentuk bahasa Arab maupun dalam bentuk bahasa Bugis. Kedatangan orang Melayu dengan membawa tradisi tulis dengan aksara Arab-Melayu tidak berarti meggeser peran bahasa Bugis Lontarak sebagai bahasa tulis-menulis, bahkan bahasa Bugis tetap eksis. Diungkapkan oleh Athony $\operatorname{Reid}^{3}$ bahwa bahasa-bahasa daerah di wilayah Indonesia lainnya seringkali ditulis dalam huruf Arab untuk keperluan tujuantujuan keagamaan, tetapi di Jawa dan Sulsel sistem tulis pra-Islam terlalu mapan untuk

\footnotetext{
${ }^{1}$ Syaparuddin, Akulturasi Islam dengan Budaya Lokal: Memahami Nilai-nilai Kearifan Lokal Masyarakat Bugis dalam membangun karakter Bangsa, dalam kumpulan Makalah Annual Conference on Islamic Studiesi (ACIS), (Bangka Belitung, 2011), hlm. 788.

${ }^{2}$ Bassam Tibbi, Islam and Cultural Accomodation of Social Change, (San Francisco: Westview Pres, 1991), h. 1.

${ }^{3}$ Anthony Reid, 'Southes Asia in the Age of Commerce 1640-1680” Terj. Muchtar Pabottingi. Asia Tenggara dalam Kurun Niaga 1450-1680. (Jakarta: Yayasan Obor Indonesia, 1992), h. 263.
} 
disingkirkan oleh bangsa Arab. Karya-karya ulama Jawa termasuk karya tafsir banyak diantaranya ditulis dalam bahasa lokal. Demikian pula ulama Bugis banyak menulis dalam bahasa lokal, termasuk beberapa kitab terjemah Alquran dan kitab tafsirnya ditulis dalam bahasa Bugis.

Pernyataan Anthony Reid, bahasa Arab-Melayu tidak menggeser aksara praIslam didukung oleh data. Proyek Naskah UNHAS telah memikrofilmkan naskah sebanyak 308 buah dan sebagian besar naskah itu ditulis dalam aksara Lontarak. Bahkan beberapa hikayat dari bahasa Melayu yang disadur dari bahasa Persia/Arab juga diterjemahkan dalam bahasa Bugis dan Makassar dengan aksara Lontarak, seperti Indraputra (Indalpatara), Syekh Mardan (Sehe Maradang), Marakarama (Marangkarama), Amir Hamzah, Sitti Sairah (Sitti Saerah), dan masih banyak hikayat lainnya. ${ }^{4}$ Sudah tampak jelas terjadi akulturasi antara Arab-Bugis. Bagaimana Proses terjadinya akulturasi Arab-Islam-Bugis dalam pengembagangan budaya Islam lokal di Sulsel? Bagaimana pula pengaruhnya terhadap pengembangan kebudayaan Islam? Tulisan ini bertujan jawaban atas kedua pertanyaan tersebut.

\section{HASIL DAN PEMBAHASAN}

\section{A. Kajian Pustaka}

\section{Pengaruh Bahasa Arab}

Tulisan mengenai bahasa, Islam, dan budaya lokal ditemukan di dalam beberapa karya terkini. Misalnya, sebuah artikel bertajuk Studi terhadap Kosakat Bahasa Arab dalam bahasa Minangkabau, ${ }^{5}$ sampai pada kesimpulan bahwa bahasa Arab mempunyai pengaruh yang sangat besar terhadap perkembangan bahasa lokal Minangkabau. Artikel, Pengaruh Bahasa Arab terhadap Perkembangan Bahasa

\footnotetext{
4 Ahmad, Rahman, Pelestarian dan Perkembangan Aksara lontarak di Sulawesi Selatan. (Jakarta: Proyek Pengkajian dan Pembinaan Nilai-Nilai Budaya Pusat, 1996), h. 35.

${ }^{5}$ Akhyar Hanif, Studi terhadap Kosakat Bahasa Arab dalam bahasa Minangkabau” Arabiyatuna : Jurnal Bahasa Arab, Vol. 1 No. 2, 2017.
} 
Indonesia ${ }^{6}$ menyimpulkan, pengaruh bahasa Bahasa Arab terhadap perkembangan bahasa Indonesia cukup besar. Mirip dengan itu, Pengaruh Bahasa Arab terhadap Perkembangan Bahasa Indonesia dan Bahasa Daerah: Peluang dan Tantangan ${ }^{7}$ juga pada akhirnya menyimpulkan bahwa bahasa Arab yang didaptasi masuk kedalam bahasa Indonesia pada mulanya dianggap sebagai bahasa asing, dan seiring perjalanan waktu dan kebutuhan maka kosakata tersebut menjadi baku dalam bahasa Indonesia dan bahasa daerah. Sedangkan pengaruh bahasa Arab terhadap pengembangan budaya lokal dan budaya Islam di luar komunitas Arab merupakan suatu kajian tersendiri.

Dalam konteks kajian ini, bahasa Arab memiliki hubungan timbal balik antara bahasa Arab, budaya lokal, dan budaya Islam pada masyarakat Bugis. Muh. Harisah di dalam skripsinya mencatat sekitar 421 kata Bugis yang terserap (dakhil) dari bahasa Arab yang disusun secara alfabet. ${ }^{8}$ Skripsi ini ditulis tahun 1978. Setelah itu, tidak ditemukan lagi tulisan yang lebih konfrehensif mengenai bahasa Arab, bahasa Bugis, dan kebudayaan Islam. Padahal, rentang waktu antara tahun 1978 dan 2018 (40 tahun) diduga kuat telah banyak mengalami dinamika dan penambahan kosakata Arab yang diadaptasi kedalam bahasa Bugis.

\section{Islam dan Budaya Lokal}

Adapun relasi Islam dan budaya lokal mempunyai daya tarik tersendiri untuk dikaji. Kajian Kritik Akulturasi Islam dengan Budaya Lokal, sebuah kajian yang dilakukan oleh Hamzah Junaid ${ }^{9}$ yang menyimpulkan bahwa hubungan keduanya bersifat dinamis. Karena dinamisnya, kearifan lokal diantaranya ada yang sejalan dengan Islam dalam masa dan ruang tertentu, ada pula yang mesti diluruskan. Islam

\footnotetext{
${ }^{6}$ Ayuba Pantu, Pengaruh Bahasa Arab terhadap Perkembangan Bahasa Indonesia, Jurnal Ulul Albab, Vol. 16 No.1, 2014.

7 I Wayan Pastika Pengaruh Bahasa Arab terhadap Perkembangan Bahasa Indonesia dan Bahasa Daerah: Peluang dan Tantangan, Jurnal Kajian Bali, Vol. 2 No. 2, 2012.

${ }^{8}$ AGH. Drs. Muh. Harisah, “Ta’tsir al-Lugah al-Arabiyyah fi al-Lugah al-Buqisiyyah”, Skripsi Sarjana Lengkap, Ujung Pandang: IAIN Alauddin, 1978, h. 98-116.

${ }^{9}$ Hamzah Junaid, Kajian Kritik Akulturasi Islam dengan Budaya Lokal, Jurnal Sulesana Vol. 8 No. 1 Tahun 2013.
} 
menempati posisi sebagai pemandu perkembangan nilai-nilai budaya lokal. Budaya Lokal dalam Perspektif Agama: Legitimasi Hukum Adat (al- 'Urf) dalam Islam adalah sebuah artikel yang ditulis oleh Agung Setiawan, ${ }^{10}$ yang menegaskan bahwa kearifan lokal atau adat (al-'urf) merupakan salah satu sumber pertimbangan yang diakomodir dalam hukum Islam yang berasaskan kaidah al- 'adatu muhakkamh. Syaparuddin yang menulis Akulturasi Islam dengan Budaya Lokal: Memahami Nilai-nilai Kearifan Lokal Masyarakat Bugis dalam membangun karakter Bangsa. ${ }^{11}$ Selain itu sebuah artikel, Akulturasi Islam dan Budaya Lokal: Memahami Nilai-Nilai Ritual Maulid Nabi di Pekalongan, yang merupakan buah pena Nihayatur Rohmah. ${ }^{12}$ Kedua tulisan tersebut memuat tentang pengaruh Islam terhadap kebudayaan lokal, akan tetapi tulisan ini seolah mengabaikan pengaruh bahasa Arab terhadap bahasa dan budaya lokal, pada bahasa sebagai bagian integral dengan budaya. Sebuah artikel bertajuk Pergumulan Islam dengan Budaya Lokal: Studi Kasus Masyarakat Samin di Dusun Jepang Bojonegoro yang dtulis oleh Nurhuda Widiana ${ }^{13}$ dan Dialektika Islam dan Budaya Lokal Jawa ditulis oleh Andik Wahyun Muqoyyidin. ${ }^{14}$ Kedua tulisan ini mengurai relasi Islam dan budaya lokal masyarakat suku Jawa.

Yusuf dan Wekke ${ }^{15}$ yang menulis sebuah artikel Menelusuri Historisitas Pembentukan Hukum Islam: Menggagas Yurisprudensi Islam Indonesia mengemukakan bahwa faktor tempat adalah salah satu variabel yang dipertimbangkan dan melakukan kesimpulan hukum Islam, selain waktu dan kondisi. Yusuf juga

${ }^{10}$ Agung Setiawan, Budaya Lokal dalam Perspektif Agama: Legitimasi Hukum Adat (al- 'Urf) dalam Islam, Jurnal Esensia, Vol. XII No. 2, 2012.

${ }^{11}$ Syaparuddin, Akulturasi Islam dengan Budaya Lokal..., h. 788.

${ }^{12}$ Nihayatur Rahmah, Akulturasi Islam dan Budaya Lokal: Memahami Nilai-Nilai Ritual Maulid Nabi di Pekalongan, Al-Mabsut, Jornal Studi Islam dan Sosial, Vol. 9 No.2, 2015.

${ }^{13}$ Nurhuda Mardiana, "Pergumulan Islam dan Budaya Lokal: Studi Kasus Masyarakat Samin di Dusun Jepang Bojonegoro”, Jurnal Teologia, Vol. 26. No. 2 Juli-Desember 2015.

${ }^{14}$ Andik Wahyun Muqoyyidin, "Dialektika Islam dan Budaya Lokal Jawa" Jurnal Ibda: Jurnal Kebudayaan Islam, Vol. 11. No. 1. 2013.

${ }^{15}$ Muhammad Yusuf dan Ismail Suardi Wekke, Menelusuri Historisitas Pembentukan Hukum Islam: Menggagas Yurisprudensi Islam Indonesia, Jurnal Tsaqafah, Vol. 8. No. 2, 2012. 
menulis Pendidikan Karakter Berbasis Qurani dan Kearifan Lokal, ${ }^{16}$ yang menyatakan bahwa pendidikan karakter yang memiliki landasan nilai yang berifat universal bersumber dari Alquran dan bersifat lokal dan temporal yang bersumber dari nilai-nilai kearifan lokal. Ia juga menulis Relevansi Nilai-Nilai Budaya Bugis dan Pemikiran Ulama Bugis: Studi Tafsir Berbahasa Bugis Karya MUI Sulsel ${ }^{17}$ yang menegaskan bahwa setiap tafsir tidak lahir dari ruang hampa, melainkan karena dialektika pemikiran penulisnya dengan budaya di mana ia berinteraksi. Kepemimpinan Perempuan dalam Perspektif Kearifan Lokal: Pemikiran Ulama Bugis dan Budaya Bugis, ${ }^{18}$ yang menegaskan kesimpulan bahwa nilai-nilai kebudayaan Bugis memiliki keserasian dengan petunjuk Alquran, sehingga ia perlu dilestarikan dalam mengahadapi tantangan global dan modernitas.

\section{Bahasa Arab dan Bahasa Bugis dalam Literasi Tafsir}

Perkembangan secara spesifik mengenai tafsir berbahasa Bugis di Sulsel telah ditulis oleh beberapa penulis misalnya tentang Tafsir Berbahasa Bugis Karya MUI Sulsel: Studi atas Metodologi dan Pemikirannya yang ditulis oleh Mursalin Junaid, Perkembangan Tafsir Alquran di Sulawesi Selatan, Disertasi Muhammad Yusuf ${ }^{19}$, dan beberapa judul yang mirip. Perbedaan kedua tulisan ini terdapat pada fokus kajiannya. Mursalin menekan pada aspek metode dan pemikirannya, sementara Yusuf menekankan pada aspek latar belakang penulisan, metode, dan pengaruhnya di masyarakat.

${ }^{16}$ Muhammad Yusf, Pendidikan Karakter Berbasis Qurani dan Kearifan Lokal, KARSA: Journal of Social dan Islamic Culture, Vol. 22 No. 1, 2015.

${ }^{17}$ Muhammad Yusuf, Relevansi Nilai-Nilai Budaya Bugis dan Pemikiran Ulama Bugis: Studi Tafsir Berbahasa Bugis Karya MUI Sulsel, Jurnal El-Harakah, Vol. 15 No. 2, 2013.

${ }^{18}$ Muhammad Yusuf, Kepemimpinan Perempuan dalam Perspektif Kearifan Lokal: Pemikiran Ulama Bugis dan Budaya Bugis, Jurnal Diskursus Islam PPs. UIN Alauddin, Vol. 1, No. 2, 2013

${ }^{19}$ Muhammad Yusuf, Perkembangan Tafsir Alquran di Sulawesi Selatan: Studi Kritis atas Tafesere Akorang Mabbasa Ogi Karya Majelsi Ulama Indonesia Sulawesi Selatan, Disertasi, Makassar: PPs UIN Alauddin, 2010. 
Selain disertasi, beberapa artikel yang betajuk Bahasa Bugis dan Penulisan Tafsir Alquran di Sulawesi Selatan ${ }^{20}$ yang menjelaskan tentang kelestraian bahasa Lontarak antara lain karena dijadikan sebagai medium tafsir lokal berbahasa Bugis. Relevansi Pemikiran Ulama Bugis dan Nilai Budaya Bugis :Studi Kasus tentang 'Iddah dalam Tafsir Berbahasa Bugis Karya MUI Sulsel. ${ }^{21}$ Artikel dengan gamblang mengemukakan, Metodologi Tafsir Berbahasa Bugis: Analisis Tafesere Akorang Mabbasa Ogi karya MUI Sulsel. ${ }^{22}$ Artikel dalam jurnal ini berhasil mengidentifikasi langkah-langkah penafsirannya. Beberapa tulisan tentang tafsir berbahasa Bugis telah dilakukan oleh sebagian orang (peneliti), hanya saja belum menghubungan tiga aspek yang sangat terkait yaitu bahasa Arab, Bahasa Bugis, dan pengaruhnya terhadap pengembangan budaya di Sulsel Indonesia. Ternyata ketiganya tidak bisa dipisahkan kerena sesuai dengan tabiat dan kebutuhan dasar manusia. Disinilah posisi tulisan menempati ruang kajian ini.

\section{Mengenal Orang Bugis-Makassar}

Sulawesi bagian Selatan didiami oleh mayoritas orang Bugis (Tau Ugi) yang terdiri dari beberapa suku dan mempunyai rumpun bahasa daerah yang beraneka ragam. Pertama, Bahasa Makassar: Bahasa yang dipergunakan oleh masyarakat yang mendiami daerah-daerah Gowa, Takalar, Jeneponto, Bantaeng, Kajang (Bulukumba), daerah Manipi (Kecamatan Sinjai Barat). Kedua, Bahasa Bugis: Dipergunakan oleh masyarakat yang mendiami daerah-daerah Sinjai, Bone, Soppeng, Wajo, Pinrang, Sidrap, Pare-Pare, Bulukumba, sebagian pula yang mendiami Pangkep, sebagian daerah Maros, sebagian Mandar, Enrekang dan sebagian Barru dan Palopo. Ketiga, Bahasa Mandar: Bahasa masyarakat yang mendiami daerah-daerah Polmas, Majene

\footnotetext{
${ }^{20}$ Muhammad Yusuf, Bahasa Bugis dan Penulisan Tafsir Alquran di Sulawesi Selatan, Jurnal al-'Ulum, Vol. 12 No. 1, 2012.

${ }^{21}$ Muhammad Yusuf, Relevansi Pemikiran Ulama Bugis dan Nilai Budaya Bugis :Studi Kasus tentang 'Iddah dalam Tafsir Berbahasa Bugis Karya MUI Sulsel, Analisis: Jurnal Studi Keislaman, Vol. 13, No. 1, 2017

${ }^{22}$ Muhammad Yusuf, Metodologi Tafsir Berbahasa Bugis: Analisis Tafesere Akorang Mabbasa Ogi karya MUI Sulsel, Sosil-Religia: Jornal Ilmu Agama dan Ilmu Sosial, Vol. 9, No. 1, 2010.
} 
dan sebagian Pinrang. Keempat, Bahasa Luwu: Terdapat 12 bahasa. Di Palopo, juga di daerah pantai kecamatan Wotu dan beberapa desa di Malili dipergunakan bahasa Bugis. Ke 12 bahasa yang dipergunakan di Luwu adalah : (1) Bahasa Bugis (2) Bahasa Baru (3) Bahasa Siko (4) Bahasa Lubung (5) Bahasa Wotu (6) Bahasa Pajabatu (7) Bahasa Mangkutana (8) Bahasa Soroako (9) Bahasa Paraso (10) Bahasa Siwa (11) Bahasa Toraja, dan (12) Bahasa Pammona. Kelima, Bahasa Toraja: Dipergunakan oleh masyarakat yang mendiami daerah Makale, Rantepao dan Masamba. Keenam, Bahasa Massenrengpulu: Dipergunakan masyarakat yang mendiami Kabupaten Enrekang dan daerah-daerah lain yang bertetangga dengannya, antara lain sedikit di Kab. Pinrang, Kab. Polmas dan Kab. Tator. ${ }^{23}$ Suku-suku tersebut selain mempunyai bahasa-bahasa tersendiri, juga mempunyai budaya-budaya khusus pula, dan itulah sebagai budaya lokal.

Budaya atau kebudayaan ialah manifestasi akal dan rasa manusia; halmana berarti pula bahwa manusialah yang menciptakan kebudayaan, atau dapat dikatakan bahwa kebudayaan bersumber dari daya cipta manusia. Jadi kebudayaan Islam adalah penjelmaan akal dan rasa manusia muslim dan bersumber dari manusia muslim itu sendiri. ${ }^{24}$ Titik tolak kebudayaan Islam itu adalah doktrin Islam itu sendiri, yang pada tingkat aktualisasinya mampu mengakomodir atau bahkan mengadopsi ekspresi kebudayaan lokal sehingga menjadi bagian integral dari peradaban Islam yang khas. Tingkat adopsi, akomodasi, dan adaptasi itu bisa berbeda antara satu wilayah dengan wilayah lain, bergantung bagaimana penyebaran Islam di daerah tertentu, dan juga tergantung pada tingkat resistensi pada tingkat lokal yang ditemui Islam. Islam tidak sekedar mengadopsi dan mengakomodasi kebudayaan lokal, melainkan juga mengangkat kebudayaan lokal ke tingkat universal. ${ }^{25}$ Terdapat nilai-nilai kearifan lokal

${ }^{23}$ A. Moein MG, Siri \& Pacce, (Makassar: SKU Makassar Press, 1977), h. 11.

${ }^{24}$ A. Hasymy, Sejarah Kebudayaan Islam (Cet. I; Jakarta: Bulan Bintang, 1975), h. 14.

25 Tim Penyusun, Ensiklopedi Tematis Dunia Islam, Jilid 1 (Jakarta: PT Ikhtiar Baru Van Hoeve, 2002), h. 320. 
yang sejalan dengan nilai-nilai universal misalnya kejujuran (lempu'), berkata benar (ada tongeng).

\section{B. Kajian Teoritis}

Persepsi umum (coomon sense) tentang kawasan Arab atau kawasan Timur Tengah bahwa mayoritas masyarakatnya berbahasa Arab dan beragama Islam. ${ }^{26} \mathrm{Hal}$ ini wajar, sebab Arab merupakan kawasan tempat pertama kalinya lahir Islam. Berbeda halnya dengan Sarjana Barat, mereka membedakan antara kawasan Arab dengan menggunakan istilah Timur Tengah. Hal ini tidak hanya karena masalah geografis, melainkan untuk menjelaskan bahwa masyarakat Timur Tengah adalah masyarakat yang heterogen. E.T. Mahan misalnya, orang pertama yang menyebut Arab sebagai Midle East untuk menyebut kawasan Arab yang terbagi kedalam beberapa kawasan, yaitu Arab bagian Afrika Utara, Arab bagian timur, Arab Teluk, dan Asia Barat. ${ }^{27}$ Artinya, harus dibedakan antara Arab secara geografis dan secara kultural. Dengan menyebut Timur Tengah maka Arab tidak selalu sama dengan Islam.

Demikian pula hubungan Islam dan Budaya. Agama dan budaya memiliki indepensi di satu sisi dan keterkaitan keduanya di sisi yang lain merupakan permasasalahan tersendiri. Lahirlah berbagai istilah untuk menunjukkan Islam dalam studi kawasan misalnya pribumisasi Islam yang diperkenalkan oleh Abdurrahman Wahid (Gusdur), ${ }^{28}$ Islam Nusantara oleh Azyumardi Azra, Keislaman dan Keindonesiaan oleh Cak Nur, dan berbagai istilah lainnya. Hal ini juga dikenal dalam kajian fikih mengenai al- 'Urf atau tradisi dan nilai-nilai lokalitas. Hal ini menjadi salah satu pertimbangan dalam penetapan kesimpulan hukum. Konsep al- 'urf sudah lama diperkenalkan oleh ulama fikih dan ulama ushul al-fiqh.

${ }^{26}$ Yoyo, Pengaruh Bahasa Arab terhadap Identitas Sosio-kultural Masyarakat Koptik di Mesir, Jurnal CMES, Vol 10 No. 1 2017, h. 2.

${ }^{27}$ A. Goldschmidr Jr \& Bouin A. A Concise History of Midle East, Hachette UK, 2015.

${ }^{28}$ Abdurrahman Wahid, Pergulatan Negara, Agama, dan Kebudayaan (Cet. 2; Depok Nusantara, 2001,), h. 79. Asep Saiful Muhtadi, Pribmisasi Islam, Ikhtiar Menggagas Fiqh Kontekstual (Cet. 1; Bandung: Pustaka Setia, 2005), h. 5. 
Dialog antara agama dan budaya adalah sebuah keniscayaan. Menurut Denys Lombard kaum muslimin sebagai suatu kebulatan adalah sesuatu yang mustahil. ${ }^{29}$ Islam di Indonesia memang tampak berbeda dengan Islam di berbagai belahan dunia lain, terutama dengan tata cara yang dilakukan di jazirah Arab. Hal ini juga memiliki akar penjelasan dengan memahami konsep Makkiyah dan Madaniyyah dalam studi Alquran. Makkiyah dan Madaniyah adalah konsep yang menjelaskan dua faktor yaitu zaman dan geografis. Konsep Makkiyah dan Madaniyyah adalah sebuah pendekatan memahami perkembangan gagasan Alquran dalam melihat faktor zaman dan geografis.

Kegagalan mempertemukan antara teks dengan pesan zaman dan pesan teritorial seringkali menjadi sebuah perdebatan yang melelahkan. Berangkat dari gagasan ini, Menjadi Islam tidak harus menjadi Arab. Islam memang lahir di Arab tetapi tidak hanya untuk masyarakat Arab. Menjadi muslim dengan tetap menjadi orang Bugis merupakan hal yang mesti diberi ruang seluas-luasnya.

Ketikan Islam datang ke sebuah wilayah maka bahasa Arab sebagai bahasa kitab suci memberikan pengaruh besar terhadap perkembangan bahasa lokal di daerah yang dimasuki Islam. Budaya mempunyai posisi untuk beradaptasi dengan nilai-nilai yang dibawa oleh Islam. Bahasa sebagai mediumnya juga tentuk ikut memberi pengaruh. Bahasa merupakan seperangkap budaya (the language is a set of culture), keduanya saling memberi pengaruh. Keduanya tidak bisa dipisahkan. Bahasa Arab adalah salah satu bahasa dunia yang paling kaya kosakatanya dan hidup terus mengalami pertumbuhan mengikuti perkembangan zaman. Faktor yang mendukung bertahannya bahasa Arab, antara lain karena al-Qur'an dan hadis Nabi Saw., dan eksteks Islam lain juga pada umumnya ditulis dalam bahasa Arab. Pada mulanya bahasa Arab yang berkembang, itu berasal dari asimilasi berbagai bahasa suku-suku yang pernah mendiami jazirah Arab. ${ }^{30}$

${ }^{29}$ Lombard, Denys, "Nusa Jawa Silang Budaya", Terj. (Jakarta: Gramedia, 1996, h 86.

${ }^{30}$ Ahmad Iskandari dkk, al-Wasith fi al-Adab al-Arabiy wa Tarikhih, (Mesir: Dar Ma'arif, t.th), h. 11 . 
Bahasa Arab sebagai bahasa al-Qur'an dan al-Sunnah turut tersebar bersama tersiarnya agama Islam di Kepulauan Nusantara sejak abad 12, kemudian berkembang dan memberi pengaruh, bukan hanya pada aspek keagamaan, melainkan juga pada aspek kebudayaan dan kebahasaan. ${ }^{31}$ Perkembangan budaya pada sebuah masyarakat mempengaruh perkembangan bahasa pada masyarakat tersebut.

Khusus pada aspek kebahasaan, bahasa Arab telah banyak memberikan kontribusi terhadap perkembangan bahasa daerah, utamanya bahasa Bugis dengan memperkaya perbendaharaan kosakata bahasanya. Kosakata bahasa Arab banyak diadopsi atau diadaptasi oleh bahasa Bugis, utamanya setelah Islam tersebar dan dianut oleh masyarakat Bugis. Pengaruh ini dapat kita lihat, antara lain pada pemberian nama orang, misalnya 'Umar (nama Arab) menjadi Ummareng (nama Bugis); Utsman menjadi Semmang, Abdu menjadi Beddu, Khattab menjadi Tabe. Demikian pula pada kata-kata yang terkait dengan ajaran Islam yang ditransfer ke dalam bahasa Bugis, seperti yang terlihat pada istilah-istilah ibadah, misalnya rukun menjadi rokong; wuquf menjadi wokkofo', dan seterusnya.

Sejalan dengan masuknya agama Islam di Sulawesi Selatan yang sumber ajaran pokoknya berdasar pada al-Qur'an dan al-Sunnah, kemudian Islam dianut oleh mayoritas penduduknya maka pengaruhnya sangat besar sekali, bukan hanya pada aspek keagamaan dan budaya tetapi juga pada aspek bahasa. Kalau dikatakan bahwa Arab identik dengan Islam, maka Bugis pun demikian pula identik dengan Islam sekalipun tidak semua orang Arab dan orang Bugis beragama Islam.

\section{Hasil dan Analisis}

Terdapat sejumlah kosakata bahasa yang telah diadaptasi kedalam bahasa Bugis yang secara sadar atau tidak, telah banyak digunakan oleh orang-orang Bugis.

I. Yang berhubungan dengan istilah-istilah dalam ibadah:
1. Ruknul Islam
menjadi
: rokonna sellengnge

${ }^{31}$ Radhi Al-Hafid, Sistem Pengajaran Bahasa Arab di Pesantren Modern IMMIM Ujung Pandang Sulawesi Selatan, Tesis (Jogjakarta: PPs IAIN Sunan Kalijaga, 1991), h. 14. 
2. Islam

3. Syahadat

4. Sujud

5. Ruku'

6. I'tidal

7. Dua'

8. Tasbih

9. Tahlil

10. Takbir

11. Tertib

12. Wirid

13. Qunut

14. Iqamat

15. I'tiqad

16. Syariah

17. Thariqah

18. Haqiqah

19. Qurban

20. 'Amal

21. 'Amil

22. Imam

23. Ma'mum

24 . Niyyat

25. Hajji

26. Umarah

27. Thawaf

28. Sa'y

29. Wuquf

30. Masjid

31. Ka'bah

32. Qubbah

33. Mimbar

34. Khutbah

35. Khatib

36. Sajadah

37. Taqlid

38. Jam' Taqdim

39. Jam' ta'khir

40. Dzikir

41. Rak'ah

42. Zakat

43. Zakatul Fithr

44. Subh
: selleng

: sada' / sahada'

: suju'

: roko'

: ittidaleng

: doang

: tasebbe

: tahelele

: takabbere'

: taratte'

: wiri'

: kunnu'

: kame'

: ateka'

: sarea'

: tareka'

: hakeka'

: karoba

: amala'

: amele'

: imang

: ma'mung / ma'amung

: nia'

: hajji

: umera

: tawwape'

: saing

: wakkopo'

: masigi' / masiji'

: kabba

: kobang

: bebara'

: katobba

: katte'

: sujjada

: takelle'

: jama' takedemeng

: jama' tahereng

: sikkiri'

: rakang

: sekke'

: sekke' pittara

: subu 
45. Dzuhr

46. 'Ashr

47. Magrib

48. 'Isya'

49. Tahajjud

50. Tarwih

51. Aurat

52. Fajr
: loro

: assara'

: mangaribi

: issa

: tahajju'

: tarawe

: ure'

: pajjareng

II. Yang berhubungan dengan nama orang:
1. Abun
menjadi
: Ambo / Ambe
2. Abu Bakrin
3. Ahmad
4. Amir
: Abu Bakkareng
5. Anas
: Hemma
6. Arasy
7. Aziz
8. Amin
9. Adam
: Amire'
10. Abduh
: Anase'
: Arase'
: Sise'
: Aming
: Adang
11. Abunawas
: Beddu
12. Arif
13. Abdullah
: Bennuase'
14. Umm
15. Umar
16. Utsman
17. Ukasyah
Arife
: Badollahi
: emma'
: Ummareng
: Semmang
18. Fathimah
: Ukkase'
19. Zainab
: Patimang / Timang
20. Maryam
21. Hafsah
22. Hindun
23. Qasim
24. Ilyas
25. Mahmud
26. Hammad
27. Hamid
28. Nashir
29. Rahman
30. Nawir
31. Nuh
32. Ismail
: Sena'
: Mariyang / Mariyama
: Pessa
: Hindong
: Kaseng
: Liyase'
: Mahemu' / Mude
: Hammade'
: Mide'
: Nasire
: Remmang / Ramang / Amang
: Nawire'
: Nuhung
: Semmaila
33. Ibrahim
: Barahima 
34. Syu'aib

35. Yunus

36. Ya'qub

37. Wahid

38. Wahab

39. Khadijah

40. Mas'ud

41. Sa'id

42. Jalil

43. Hafidz

44. Karim

45. Yahya
: Sebe'

: Nusu'

: Kube'

: Wahe'

: Habe'

: Halijah

: Maseude / Saude'

: Saide'

: Jalile'

: Pile'

: Karing

: Hiyya

III. Yang bertalian dengan nama-nama bulan Qamariyah:
1. Muharram
2. Shafar
3. Rabiul Awal
menjadi
: Muharrang
4. Rabiul Akhir
: Sapareng
5. Jumadil Awal
: Rabiule awali
6. Jumadil Akhir
: Rabiule ahiri
7. Rajab
: Jumadile awali
: Jumadile akhiri
8. Sya'ban
: Rajja'
9. Ramadhan
10. Syawal
: Sabang
11. Dzulqaiddah
: Ramalang
: Sawwaleng
12. Dzulhijjah
: Sulekaedda
: Sulehajji

IV. Yang berhubungan dengan nama-nama hari:
1. al-Sabtu
2. al-Ahad
3. al-Itsnain
4. al-Tsulatsa
5. al-Arbia
6. al-Khamis
7. al-Jum'ah

$\begin{array}{ll}\text { menjadi } & : \text { Sattu } \\ & : \text { Aha' } \\ & : \text { Aseneng } \\ & : \text { Salasa } \\ & : \text { Arabang } \\ & : \text { Kammisi } \\ & : \text { Juma' }\end{array}$

V. Yang berkaitan dengan nama-nama mata pelajaran dan yang terkait dengannya:
1. Qur'an
2. Tafsir
3. Hadits
4. Fiqih
5. Akhlaq
6. Tashawwuf

$\begin{array}{ll}\text { menjadi } & : \text { Akorang } \\ & : \text { Tepesere } \\ & : \text { Haddise' } \\ & : \text { Fikihi } \\ & : \text { Ahlake' } \\ & : \text { Tassaupu }\end{array}$


7. Nahw

8. Sharf

9. Faraidh

10. Tajwid

11. I'rab

12. Fi'l

13. Ism

14. Mubtada'

15. Khabar

16. Jar-majrur

17. Dhamir

18. Dzahir

19. Fa'il

20. Maf'ul

21. Tahjjiy

22. Mabni Ma'lum

23. Mabni Majhul

24. Hal

25. Tamyiz

26. Badl

27. Taukid

28. Athf

29. Shifah

30. Dars
: Nahawu

: Sarape'

: Paraileng

: Tajawi'

: mangera'

: pele

: ising

: mubetada

: habbareng

: jarang-majeroro

: lamere

: lahereng

: paileng

: mapeuleng

: mangeja

: mabeni ma'lomeng

: mabeni majeholo

: haling

: tameyise

: baddaleng

: take'

: atape'

: sipa'

: darasa'

VI. Yang berhubungan dengan alat tulis menulis:
1. Qalam
menjadi
: kallang
2. Kitab
: kitta'
3. Qirthas
: karetasa
4. Dawat
: dawa'

VII. Yang berhubungan dengan hukum:
1. Hokum
menjadi
: hukkung
2. Had
: hadde
3. 'Adil
: adele'
4. Wajib
5. Haram
: waji'
6. Sunnah
: Harang
7. Makruh
: Sunna
8. Akhirat
: makero
9. Nikah
: ahera'
10. Thalaq
11. Ruju'
: nikka
: telle
12. Quru'
: ruju'
: koro 
Masih ada lagi beberapa kata dalam dalam bahasa Bugis yang mirip dengan bahasa Arab namun belum bisa dipastikan apakah itu memang berasal dari bahasa Arab atau hanya secara kebetulan mirip bunyinya dan sepadan makna pemakaiannya, seperti yang diangkat oleh Muh. Harisah dalam Skripsinya, antara lain sebagai berikut ${ }^{32}$ :
1. Maladde
dari

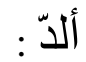
2. Balatu'
بلاط:
3. Maddoja

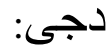
4. Maddese'
دس:
5. Mapparape'
رفع:
6. Massolo'
سال:
7. Sulara'

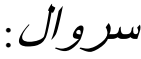
8. Siri
سر:
9. Cippe'
شفت:
10. Naredde
11. Bukka

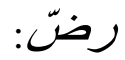
12. Telling
13. Nadadai
14. Napassalai
15. Putu
فلّك:
16. Genne'
17. Masagena
18. Sikere'
طل:
عضد :
فصلّ:
19. Malleppe'
فطور: فصن:
غنسى:

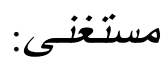
قير/ط:
20. Lana-lana
لف : لَّ:
21. Melo
مان:
22. Maggalelu'
مال:
23. Rapa-rapa
قبلولة:
24. Mallung

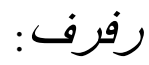
مظل:

${ }^{32}$ Radhi Al-Hafid, Sistem Pengajaran Bahasa Arab .... h. 117. 
Secara umum kebudayaan meliputi tujuh unsur, yaitu: (1) bahasa, (2) sistem pengetahuan, (3) organisasi sosial, (4) sistem peralatan hidup dan teknologi, (5) sistem mata pencaharian, (6) sistem religi, dan (7) kesenian. ${ }^{33}$

Islam mulai masuk dan berkembang di Sulawesi Selatan pada tahun $1605 \mathrm{M}$ $(1015 \mathrm{H})$ ketika raja Gowa Bersama Mangkubuminya (Raja Tallo) menyatakan dirinya memeluk agama Islam lalu digelar dengan Abdullah Awwalul Islam, kemudian menyusul Raja Gowa yang bergelar Sultan Alauddin. ${ }^{34}$ Adapun nama asli Raja Tallo ialah I Mallingkaan Daeng Manyonri', sedangkan nama asli raja Gowa I Mangerangi Daeng Manrabbiya. ${ }^{35}$ Dr. Hamka mencatat bahwa Islam masuk secara resmi di kerajaan Gowa dan Bone pada tahun 1602 atau 1603 dan Raja Gowa menerima Islam dari 3 orang guru agama Islam yang datang dari Minangkabau, yaitu Datuk Ri Bandang, Datuk Ri Tiro dan Datuk Patimang. Lalu beliau menyatakan bahwa sebenarnya orang-orang Islam pendatang telah ada di Gowa jauh sebelum Raja Gowa menerima Islam secara resmi yaitu sekitar tahun $1540 .{ }^{36}$

Orang Bugis mempunyai pedoman dasar di dalam segala hal yang akan mereka perlakukan baik dalam bentuk tindakan maupun dalam bentuk ucapan sebagai landasan berupa tatakrama, tata tertib yang dinamai dengan Pangadereng (aturan-aturan, adat, sistem, atau norma). Mattulada menjelaskan bahwa sebelum Islam dating ke Sulawesi Selatan, Pangadereng terdiri dari empat unsur, yaitu (1) Ade' ; (2) Bicara; (3) Rapang; dan (4) Wari'. Setelah Islam datang maka Pangadereng ditambah lagi satu unsur yaitu unsur Sara' sehingga lengkap menjadi lima unsur. Ade' adalah sistem norma dan aturan-aturan dalam kehidupan masyarakat yang meliputi segala keharusan bertingkah laku dalam semua kegiatan kehidupan. Ade' berarti tata tertib yang bersifat normatif,

${ }^{33}$ Tim Penyusun, Ensiklopedi Nasional Indonesia, Jilid 3, (Jakarta: PT Cipta Adi Pustaka, 1989), h. 496.

${ }^{34}$ Abd. Rahman Getteng, Pendidikan Islam di Sulawesi Selatan Tinjauan Historis dari Tradisional hingga Modern, Cet. I (Yogyakarta: Graha Guru, 2005), h. 60. Lihat pula, Ensiklopedi Tematis Dunia Islam, Jilid 5, (Jakarta: PT Ikhtiar Baru Van Hoeve), h. 51.

${ }^{35}$ Lihat, Laside Dg. Tapala, Lontara'na Petta Malampe-E Gemmenna, (Ujung Pandang: Yayasan Lektur Batu Putih, 1971), h. 12, 19.

${ }^{36}$ Lihat Hamka, Sejarah Ummat Islam, Jilid IV, (Cet. 2; Jakarta: Bulan Bintang, 1976), h. 288. 
memberi pedoman kepada sikap hidup dalam menghadapi, menanggapi dan menciptakan hidup kebudayaan baik ideologis, mental spiritual maupun fisik. Bicara ialah yang bertalian dengan masalah peradilan. Rapang ialah yang bertalian dengan upaya mempertahankan tradisi dan etika kehidupan berkelanjutan. Wari' ialah memelihara klasifikasi, tata urutan ketertiban berkehidupan, kekeluargaan dan hubungan antar negara. Sara' ialah syariat Islam yang memberikan isi Pangadereng dengan semangat iman dan akidah Islam. ${ }^{37}$

Dengan dimasukkannya unsur sara' ini kedalam Pangadereng maka Islam mempunyai ruang dan peluang untuk lebih leluasa masuk mempengaruhi, melengkapi dan meningkatkan budaya lokal yang sudah ada sebelumnya maupun budaya baru yang akan terbentuk kemudian. Penggunaan istilah Sara' menunjukkan bahwa budaya orang Bugis itu budaya Islam, sebab kata sara' itu berasal dari istilah Arab dan Islam, yaitu syara' (agama). Dari sinilah orang Bugis-Makassar menyandingkan budaya dan Islam.

Unsur yang pertama pada Pangadereng tersebut sudah terdapat pengaruh Islam karena kata ade' berasal dari bahasa Arab adatun yang berarti kebiasaan yang semakna dengan urfun atau ma'ruufun yaitu segala perbuatan yang sudah biasa dilakukan dan dimaklumi bersama kebaikannya, lawannya munkarun.

Tidak ditemukan istilah kebudayaan dalam kosakata Bugis. Apabila pengertian ade' dan pangadereng hendak dipahami berdasarkan konsep kebudayaan, maka ade' mengandung pengertian umum sedangkan pangadereng mengandung pengertian terbatas. $^{38}$

Selain kelima unsur yang terkandung dalam Pangadereng yang harus dipedomani oleh orang Bugis dalam hidup bermasyarakat, ada lagi satu unsur yang tidak kalah pentingnya untuk harus selalu dijaga di dalam menjalankan pangadereng yaitu unsur siri' (budaya siri').

37 Mattulada dalam Demokrasi dalam perspektif Budaya Nusantara, Edit. Mohammad Najib, dkk. ( Cet. I; Yogyakarta: LKPSM, 1996), h. 41, 43.

${ }^{38}$ A. Rahman Rahim, Nilai-Nilai Utama Kebudayaan Bugis, (Ujungpandang: LEPHAS, 1985), h. 136 . 
Siri' dalam bahasa Bugis berarti "malu". Menurut Cassuto seperti yang dikutip M.Natsir Said, siri' merupakan pembalasan yang berupa kewajiban moril untuk membunuh pihak yang melanggar adat. ${ }^{39}$ Setelah mengemukakan beberapa pendapat pakar tentang arti siri', M. Natsir Said menarik kesimpulan: "Siri' adalah suatu perasaan malu yang dapat menimbulkan sanksi dari keluarga/family yang dilanggar norma adatnya". ${ }^{40}$

Seorang antropolog Amerika, Shelly Errington pernah mengadakan penelitian di Luwu' (1976-1977) mengemukakan arti siri' sebagai berikut:

... untuk orang Bugis tidak ada tujuan atau alasan hidup lebih tinggi atau lebih penting daripada menjaga siri'-nya, dan kalau merasa tersinggung, atau ripakasiri' (dipermalukan), ia merasa lebih senang mati dengan perkelahian untuk memulihkan siri'-nya daripada hidup tanpa siri'. Dan memang orang Bugis-Makassar terkenal di mana-mana di Indonesia karena dengan mudah mereka suka berkelahi kalau diperlakukan tidak sesuai dengan derajatnya. Meninggal karena siri' dikatakan mate ri gollai, mate risantangi, artinya mati diberi gula dan santan, yaitu mati untuk sesuatu yang berguna. ${ }^{41}$

Nilai budaya siri' merupakan salah satu pedoman penting dalam kehidupan orang Bugis. Siri' merupakan pandangan hidup yang wajib dipertahankan oleh orang Bugis selama hidupnya, karena menyangkut harga diri dan kehormatan. Siri' dalam arti membela dan mempertahankan harga diri tidak bertentangan dengan ajaran Islam, sebagaimana diwajibkannya pula mempertahankan harta milik dan agama. Hanya dalam kenyataannya, sering siri' itu dilaksanakan terlalu melampaui batas, sering terjadi hanya karena gara-gara sepele saja mengakibatkan melayangnya jiwa seseorang. Di sinilah perlunya pemberian pemahaman agama yang benar agar pelaksanaan siri' sejalan dengan yang diajarkan oleh Islam.

${ }^{39}$ M. Natsir Said, Siri' dan Hubungannya dengan Perkawinan masyarakat Mangkasara Sulawesi Selatan (Cet. I; Makassar: Sejahtera, 1962), h. 50.

50.

${ }^{40}$ M. Natsir Said, Siri' dan Hubungannya dengan Perkawinan masyarakat Mangkasara..., h.

${ }^{41}$ Andi Zainal Abidin Farid dalam Siri' dan Pesse, Ed. Muh. Yahya Mustafa dkk, (Makassar: Pustaka Reflexi, 2003), h. 14-15. 
Di dalam masyarakat Bugis ditemukan beberapa komunitas tertentu yang menganut semacam aliran atau tradisi yang menjadi kekhususan daerah tertentu di samping adanya tradisi-tradisi yang sering dilakukan oleh masyarakat secara umum di mana tradisi tersebut seakan menjadi milik bersama yang biasa ditampilkan pada upacara-upacara atau pesta-pesta tertentu. Sebagai contoh, Maudu' Lompoa di Cekoang, Gattarang keke di Bulukumba, Patuntung di Kajang, Tolotang di Sidrap, Bissu di Labbakkang (Pangkep), Haji Bawakaraeng di Pangkep dan Bulukumba. Budaya-budaya lokal tersebut pada umumnya erat hubungannya dengan suatu sistem kepercayaan bagi suatu komunitas tertentu.

Selain itu, ditemukan pula dalam masyarakat Bugis beberapa corak tradisi yang dilakukan ketika mereka mengadakan suatu hajatan. Tradisi ini diwarisi secara turuntemurun, dari generasi ke generasi, misalnya tradisi pembacaan Kitab Barzanji ketika mereka naik atau masuk rumah baru, akad nikah (biasanya dilakukan pada acara mappacci/tudang penni), aqiqah dan yang paling banyak disaksikan sekarang pembacaan Kitab Barzanji dilakukan ketika ada di antara anggota keluarga mereka menunaikan ibadah haji dan itu dilakukan pada tiap malam jumat sampai jamaah hajinya pulang. Selain itu, juga dijumpai tradisi mabbaca doang dan mattampung yaitu upacara pemotongan kerbau atau sapi bagi seorang yang meninggal dunia, biasanya dilakukan ketika si mayit genap tiga hari atau tujuh hari, empat puluh hari dan seratus hari wafatnya. Upacara ini sering diistilahkan dengan tahlilan.

Jika diperhatikan praktek-praktek tersebut tentunya tidak semua dapat dibenarkan apabila diukur dengan kacamata Agama (Islam). Ada yang perlu diluruskan, ada yang harus disempurnakan, dan ada yang mesti diganti dengan yang lebih baik dan benar. Di sinilah diharapkan peran aktifnya para muballig mengadakan pendekatan kepada mereka dengan menggunakan metode dakwah bil-hikmah wal mauidzatul hasanah, tanpa perlu mengucilkan mereka, membenci, apalagi menggunakan kekerasan. 
Selain praktek-praktek yang ada hubungannya dengan suatu kepercayaan atau agama seperti disebutkan di atas, orang Bugis juga memiliki suatu hasil karya sastera yang mempunyai nilai seni tinggi, yaitu Elong Ugi.

Elong Ugi (nyanyian bugis dalam bentuk puisi) banyak jenisnya, antara lain : (1) Elong sipacaddio-rio (dituturkan pada waktu bergembira-ria) yang terdiri dari elong mabbotampatang (dituturkan secara bersahut-sahutan), elong mareja-eja (dinyanyikan pada saat mempelai sementara duduk bersanding), elong padondo ana' (dinyanyikan agar sianak dapat tidur cepat), elong yabe lale (nina bobok), elong tuntumpenek (pengundi); (2) Elong Assimelerreng (nyanyian berkasih-kasihan); (3) Elong Silebbai (saling membenci); (4) Elong Pangaja (nasehat); (5) Elong Osong (Pembangkit semangat prajurit menghadapi perang) dan Elong Aruk (diucapkan oleh seorang Panglima dihadapan raja sebagai tanda dukungan dan kesetiaan). ${ }^{42}$

Semua jenis elong tersebut di atas agaknya sudah terlupakan oleh generasi sekarang, mungkin karena tertelan oleh nyanyian-nyanyian modern yang semakin menggila. Diakui bahwa elong ugi yang memang telah ada, tidak hanya mungkin mengalami perubahan bentuk sejalan dengan penuturannya dari mulut kemulut melainkan besar kemungkinan ia pun akan mengalami pergeseran frekuensi pemakaian dari waktu ke waktu sesuai dengan pergeseran nilai-nilai sosial budaya yang terjadi dan akhirnya ia tercecer dan terlupakan.

Elong Ugi sebagai karya sastra merupakan bagian dari kebudayaan yang tumbuh dan berkembang di tengah-tengah masyarakat Bugis dan menjadi milik bersama dan ia tidak hanya berfungsi sebagai alat hiburan, pengisi waktu lowong serta penyalur perasaan bagi penutur dan pendengarnya, melainkan juga berfungsi sebagai pencerminan pandangan, sikap, alat pendidikan anak serta pemeliharaan norma-norma masyarakat. Diantara elong (lagu) Bugis yang ditemukan dan mengandung nilai-nilai yang dalam dan senafas dengan Islam yaitu Elong Pangaja.

${ }^{42}$ Lihat Drs. Mahmud, Kedudukan dan Fungsi Elong Ugi (Cet. I; Makassar: Pesantren UP, 1993), h. 25-47. 


\section{ELONG PANGAJA}

Matutuo ri teppe'mu

Aja' muilimpiling

Rikasiwiyammu

Tunru'kko makkasiwiyang

Muwappuji temmangingngi

Sada' munennungeng

Mannennungekko puada

Sada' mappattongneng

Rilaleng atimmu

Ati telling mappattongeng

Tubu mekkeda ada

Ibada tentuang

Sada' tentu ritentuang

Tonging naripattongeng

Pejeppusai

Pejeppui tongengsai

Isseng mannessatoi

Riakkuwanae

Pura kuwai tarona

Nabitta singgkerrui

Ri laleng atimmu

Mappejeppu tongengtoi

Cemmewa satinja

Pepaccingitoi

Pepaccing tongengsai

Isseng manessatoi

Riakkuannae

Nawa-nawasai

Linoe talolangi

Tettosipuppureng

Ia tennasipuppureng

Lino rimalalana

Tubue nyawana

Benengnge temmalalai

Nyawae, bokoriwi

Lompengeng ri maje 
Oncoppi rimalalana

Lino, apa tania

Idi sepammulang

Mauni simula mulang

Lino pura totona

Tessiallampereng

Lagu atau nyanyian Bugis ini selain mengandung nilai-nilai sastra Bugis yang mendalam, juga mengandung nilai-nilai utama yang memiliki nilai-nilai spritual yang tinggi tentang hakikat hidup dan hakikat manusia. Sebagaimana telah disebutkan di atas bahwa salah satu dari tujuh unsur kebudayaan ialah kesenian. Seni sebagai hasil budaya manusia tidak terlarang di dalam ajaran Islam, tetapi harus dipertimbangkan misi yang terkandung di dalamnya, apakah tidak terdapat hal-hal yang melanggar norma agama.

Harus dipahami bahwa kesenian Islam mesti bertumpu pada akidah tauhid, dan seni bukanlah termasuk al-dharuriyyat (kebutuhan mendesak) bahkan bukan al-hajiyat (kebutuhan pokok) tetapi hanya sebagai al-tahsiniyat atau al-kamaliyat (pelengkap) yaitu hanya merupakan kebutuhan sekunder. Kesenian Islam bukanlah sebagai tujuan, tetapi hanya sebagai wasilah (alat atau sarana), karena seni, menurut Islam, bukanlah semata untuk seni, tetapi seni untuk mewujudkan kebenaran, moral dan keadilan. ${ }^{43}$

Al-Aqqad menegaskan bahwa tidak satu pun kata dalam Al-Qur'an yang menunjukkan adanya larangan terhadap karya seni. Demikian pula tidak ada kata pasti tentang pengharaman suatu karya seni selain yang dibuat untuk sesembahan. Ia merujuk beberapa ayat Al-Qur'an yang mengandung isyarat bahwa yang indah itu merupakan tanda-tanda kebesaran-Nya dan sebagai nikmat kepada hamba-Nya. Ayatayat itu antara lain, QS. Al-Kahf (18): 7, al-Hijr (15): 16, Qaf (50): 6 dan al-A'raf (7): 31-32. Juga ia banyak menyebutkan hadis, di antaranya hadis yang artinya: Sesungguhnya Allah Maha Indah, senang kepada yang indah. Yang menjadi kaidah 1990), h. 36.

${ }^{43}$ Shalih Ahmad al-Syamiy, al-Fann al-Islamiy Iltizam wa Ibtida' (Damaskus: Dar al-Qalam, 
umum dalam Islam, menurut al-Aqqad, ialah tidak ada pengharaman terhadap sesuatu selama tidak mengandung mudarat atau adanya kekhawatiran akan terjadinya bahaya. Adapun kalau sesuatu itu nyata-nyata mengandung manfaat tidak boleh sama sekali dilarang, karena bila dilarang berarti meninggalkan maslahat. ${ }^{44}$

\section{d. Bahasa Bugis dan Literasi Tafsir Lokal}

Sejak pengembangan dakwah Islam, orang-orang Melayu yang berdiam di Makassar telah memegang peranan penting, terutama dalam penulisan dan penyalinan buku-buku agama Islam dari bahasa Melayu ke bahasa Bugis-Makassar (lontara). Berbagai lontara yang asalnyadari bahasa Melayu, diduga berasal dari zaman perkembangan Islam di Sul-Sel (abad XVII-XVIII), yang sampai sekarang populer dikalangan orang tua-tua Bugis-Makassar, ${ }^{45}$ antara lain: 1) Lontarakperkawinan antara Saidina Ali dengan Fatimah, putera Rasulullah; 2) Lontara Nabi Yusuf dan percintaan Laila dan Majunu; 3) Sura' bukkuru' yang dikenal dengan lontarak pau-paunna Sultanul Injilai; 4) Kitta' Faraid (hukum kewarisan); 5) Lontara Sehe Maradang; 6) Lontara tentang peperangan Nabi Muhammad dengan raja Hindi; 7) Berbagai mukjizat Nabi Muhammad, dan lain-lainnya. ${ }^{46}$ Analisis Mahmud Yunus ${ }^{47}$ tentang sistem pendidikan Islam pertama di Indonesia bahwa al-Qur'an telah diperkenalkan pada setiap Muslim sejak kecil melalui kegiatan yang dinamai "Pengajian alQur'an" di surau, langgar, dan masjid. Yunus mengklaim bahwa pendidikan al-Qur'an waktu itu adalah pendidikan Islam pertama yang diberikan kepada anak-anak didik, sebelum diperkenalkan dengan praktik-praktik ibadah (fiqh). Karel. A. Steenbrink ${ }^{48}$

\footnotetext{
${ }^{44}$ Lihat Abbas Mahmud al-Aqqad, al-Islamiyat, Jilid V (Cet. I; Bairut: Dar al-Kitab al-Lubnaniy, 1974), h. 249.

${ }^{45}$ Muhammad Yusuf, "Bahasa Bugis dan Penulisan Tafsir di Sulawesi Selatan”, Jurnal al-Ulum, Vol. 12, No. 1. Juni 2012, h. 87.

46 Taufiq, Abdullah. (ed). Agama dan Perubahan Sosial (Cet. 3; Jakarta: PT. Rajawali, 1983), h. 238.

${ }^{47}$ Mahmud Yunus ,Sejarah Pendidikan Islam di Indonesia (Jakarta: Hidakarya Agung, 1984), h. 24.

${ }^{48}$ Karel, A. Steenbrink. Pesantren Madrasah Sekolah, Pendidikan Islam dalam Kurun Modern (Jakarta: LP3ES, 1994), h. 10.
} 
memberikan kesimpulan yang sama. Lebih jauh ia menjelaskan, bahwa pengajaran alQur'an merupakan pelajaran membaca beberapa bagian al-Qur'an. Untuk permulaan, anak diajari surah al-Fatihah dan kemudian surahsurah pendek dalam juz 'Amma terdiri dari surah 78-114, para murid mempelajari huruf-huruf Arab dan menghafalkan teks-teks yang ada dalam al-Qur'an itu.

Dalam konteks wilayah Sul-Sel literatur seputar al-Qur'an kurangnya data yang ditemukan, sehingga menyulitkan untuk mengetahui sejauhmana peran intelektual SulSel dalam memperlakukan al-Qur'an. Paling tidak, bisa diungkap melalui sebuah karya proyek pembinaan perguruan tinggi agama IAIN pada tahun 1982 didapatkan bahwa karya seputar kajian al-Qur'an di wilayah SulSel hanya sekitar 15 buku, sementara kajian seputar hukum (fiqh) sekitar 42 buah buku dan dalam bidang akidah dan akhlak hanya sekitar 27 buah buku. Hal ini juga mengindikasikan bahwa kajian seputar fiqh di wilayah Sul-Sel jauh lebih tinggi dibanding kajian bidang lainnya walaupun tidak terlepas dari ayat-ayat al-Qur'an. . Di wilayah Sul-Sel pada awal-awal perkembangan Islam hampir tidak ditemukan suatu karya khusus dalam bidang tafsir. Di Sul-Sel kita kenal sosok Syekh Yusuf seorang ulama yang sangat dikagumi dan sangat produktif dalam menuangkan pikiran-pikirannya di atas kertas, tetapi penulusuran penulis mengenai karya tulisnya belum ditemukan karya khusus dalam bidang tafsir. ${ }^{49}$

Ada beberapa faktor yang menyebabkan perkembangan tafsir di wilayah Nusantara tidak begitu sepesat dengan perkembangan keilmuan lain, pada awal masuknya Islam sampai abad ke-19, menurut Nasharuddin Baidan. ${ }^{50}$ Tafsir secara langsung dari al-Qur'an dianggap tidak begitu diperlukan karena kebutuhan itu dapat dipenuhi oleh kitabkitab fiqhi, tasawuf, dan tauhid; 2. Belajar tafsir secara lansung memerlukan kemampuan bahasa Arab yang baik, Sementara memperlajari bahasa Arab memerlukan waktu yang panjang;

\footnotetext{
${ }^{49}$ Nabilah, Lubis, Syekh Yusuf, Menyingkap Intisari Segala Rahasia (Cet I; Bandung: Mizan, 1996), h. 29-30.

${ }^{50}$ Nasharuddin Baidan, Perkembangan Tafsir Al-Qur'an di Indonesia. (Cet. I; Solo: Tiga Serangkai, 2003), h. 77.
} 
Munculnya anggapan bahwa untuk mendapatkan ilmu tafsir memerlukan waktu panjang dengan melalui amaliyah seharihari, misalnya, salat, puasa dan lainlain.Setelah abad ke-20, para intelektual Muslim di Sul-Sel sudah mulai ada karya tafsir, namun penyajiannya masih berkonsentrasi pada ayat-ayat tertentu, misalnya yang termuat dalam majalah yang ditulis oleh AG. H. Muhammad As'ad, yaitu Majalah al-Maw'izhah al-Hasanah. Di dalamnya ada satu rubrik yang membahas tentang tafsir satu ayat. Pada tahun 1948 ia menulis sebuah buku tafsir kecil terbit di Sengkang, ditulis dalam tiga bahasa; Arab/Bugis/Indonesia: Tafsir bahasa Boegisnya Soerah Amma/tpEeser biCr aogin sur am" AG.H.M. As'ad. ${ }^{51}$

Pada tahun 1958, AG. H.M. Yunus Martan ${ }^{52}$ menulis karya tafsir al-Qur'an dalam bahasa Bugis yang terdiri dari tiga juz, yakni juz I, II, dan III. Judulnya ditulis dalam dua bahasa, Arab dan Bugis. Juz ketiga, yang terakhir dalam seri itu, dicetak pertama kali pada tahun 1961 AG. H.M. Yunus Martan: Format yang digunakan oleh AG. H.M. Yunus Martan adalah menuliskan teks ayat yang diikuti dengan terjemahnya. Apabila dibutuhkan "tafsir" atau penjelasan, ia menulisnya setelah terjemahnya, di bawah judul pappannessa (tafsir, penjelasan) tetapi tidak semua ayat diberi penjelasan. Pada tahun 1978, seorang guru senior dari Madrasah As'adiyah Sengkang, AG. H. Hamzah Manguluang, ${ }^{53}$ juga membuat sebuah karya terjemah alQur'ân berbahasa Bugis. Format yang digunakannya adalah membuat dua kolom dalam setiap halaman. Di kolom sebelah kiri, ia menuliskan ayat-ayat al-Qur'ân, sedangkan terjemahnya ditulis di kolom sebelah kanan. Pada sebagian besar halaman bagian bawah kitab itu, terdapat penjelasan singkat dari ayat tertentu, yang ditulis di bawah garis pemisah sepanjang halaman di bawah dua kolomnya.

513 AGH.M. As’ad,. Tafsîr Sûrah 'Amma bi al-Lughah al-Bûqisiyyah, Tafséré Bicara Ogina Surah 'Amma, di-Indonesia-kan oleh muridnya ,Sjamsoeddin (Sengkang: Adil, t.th), h. 7.

${ }^{52}$ AG. H.M. Yunus Martan.. Tafsir al-Qur'ân al-Karîm bi al-Lughah alBûqisiyyah, Tafséré Akorang Bettuwang Bicara Ogi, (Juz Tilkarrusul), (Cet. I., (Sengkang: Adil, 1381 H/1961 M), h. 66.

53 AGH. Hamzah, Manguluang. Tarjumah al-Qur'ân al-Karîm, Tarjumana Akorang Malebbié Mabbicara Ogi, juz I-X, jilid I.( Ujung (Pandang: Toko Buku Pesantren, 1985), h. 77. 
Menurut informasi yang terdapat dalam mukaddimah karya tulis ini, terjemahan al-Qur'ân yang diusahakan oleh penulisnya lengkap 30 juz, dibukukan dalam tiga jilid, setiap jilid memuat terjemahan sepuluh juz dari al-Qur'ân. Kitab ini diberi kata pengantar oleh AG. H. Daud Ismail, yang antara lain menyebutkan bahwa AG. H. Hamzah Manguluang memperoleh kemuliaan menerjemahkan al-Qur'ân 30 juz, yang belum pernah dilakukan orang sebelumnya di daerah Bugis. Kemudian belakangan muncullah tafsir lengkap 30 juz, baik ditulis oleh perorangan misalnya Tafsîr al-Munîr karya AG. Daud Ismail, maupun dalam satu tim misalnya Tafesere Akorang Mabbasa Ogi (Tafsir Al-Qur'an Berbahasa Bugis) masing-masing menggunakan aksara Lontarak karya Tim Majelis Ulama Indonesia Sulawesi Selatan terbit tahun 1988 dan lengkap 30 juz pada tahun 1996. Hingga saat, geliat penerjemahan dan penulisan tafsir berbahasa Bugis makain memiliki daya tarik tersendiri.

\section{PENUTUP}

Pengaruh Bahasa Arab terhadap bahasa Bugis tidak mengalami kendala karena Islam diterima oleh mayoritas orang Bugis, sehingga dapat dikatakan bahwa Bugis identik dengan Islam sebagaimana Arab identik dengan Islam. Orang Bugis telah mempunyai pedoman dasar berupa aturan-aturan, norma dan tatakrama yang menjadi penuntun dalam kehidupan bermasyarakat yang disebut dengan Pangadereng dan Siri'. Bahasa Arab memiliki pengaruh yang sangat signifikan terhadap bahasa lokal. Istilahistilah Islam yang berbahasa Arab kadang-kadang tidak perlu lagi dicari padanannya dalan bahasa Bugis, sebab masyarakat Bugis telah mengira sebagai bahasa lokalnya. Para muballigh, kyai, dan masyarakat santri telah berjasa besar dalam mempercepat pengaruh bahasa Arab dan istilah Islam berakulturasi dengan budaya lokal. Sistem sara' sebagai bagian dari Pangadereng telah memberikan peluang yang luas bagi akselerasi pengaruh bahasa Arab dan budaya dalam mengembangkan kebudayaan Islam di Sulawesi Selatan. Untuk pengembangan budaya Islam di Sulawesi Selatan 
perlu pembentukan wadah yang menangani secara serius dengan mengadakan infentarisasi budaya-budaya lokal, lalu dipelajari secara mendalam untuk selanjutnya ditindaklanjuti demi peningkatan dan pemeliharaannya. Makna kata siri' dan prakteknya perlu diluruskan sehingga tidak terjadi pemahaman yang keliru sehingga bertentangan dengan hakekat siri' itu sendiri. Aksara Lontarak yang akhir-akhir ini seakan-akan terlupakan perlu diangkat kembali dan memasukkannya ke dalam kurikulum sekolah utamanya di tingkat dasar. Menulis karya-karya ulama dan umat Islam dengan menggunakan aksara Lontarak seperti terjemah dan tafsir Alquran berbahasa Bugis adalah ikhtiar melestaraikan nilai-nilai kearifan lokal Bugis yang khas. Seni sebagai bagian dan kebudayaan dan elong (lagu) sebagai bagian dari seni, maka Elong Ugi yang diwarisi secara turun temurun dari mulut kemulut perlu disosialisasikan lewat tulisan-tulisan atau lewat kaset. Elong Ugi yang kurang mendapat perhatian dari generasi muda perlu diadakan modifikasi atau penciptaan elong baru yang sesuai dengan perkembangan zaman. Untuk mengimbangi munculnya lagu-lagu yang bertentangan dengan nilai-nilai kearifan lokal dan Islam, maka dibutuhkan adanya bangunan sanggar-sanggar seni dan rumah-rumah produksi lokalislami untuk memberikan ruang ekspresi bagi pecinta seni dari tanah Bugis. Bahkan bisa menjadi sumber eko-wisata budaya Islami yang mendidik dan meningkat karakter mulia. Keberadaan To Panrita, (ulama), parewa sara', tokoh adat, dan pemerintah adalah cara terbaik untuk mewujudkan hal tersebut. 